\title{
Short-tailed Shrew North of the North Saskatchewan River
}

\section{By R. W. Nero, Saskatchewan Museum of Natural History}

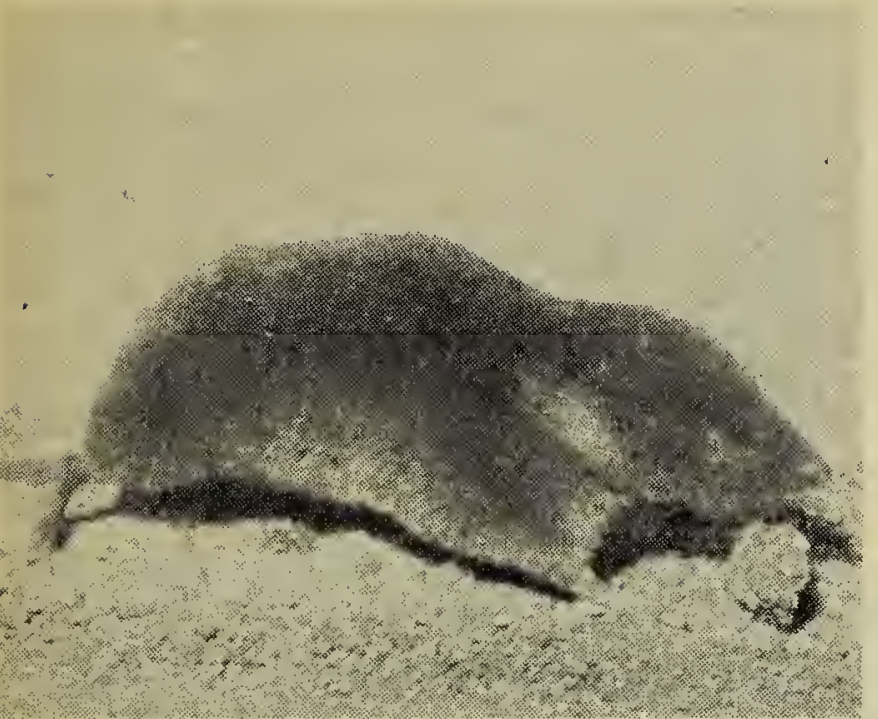

S.M.N.H. Photo

Short-tailed Shrew. Reprinted from Beck's Guide to Sask. Mammals (1958).

A Short-tailed Shrew (Blarina brevicauda) trapped on December 16, 1959 , by A. P. Pym at Keatley, Saskatchewan, extends the known range of this species nearly 90 miles west, to represent the westernmosit record and the first reported record north of the entire Saskatchewan River system (see map). The Shrew was kindly submitted to the Museum by $\mathrm{Mr}$. Pym and has been prepared as a study specimen (S.M.N.H. \#7246); it is a female.

Four years ago the question was asked in the Blue Jay: "Did Shorttailed Shrews ever cross the Saskatchewan River? Or is this the northern and western barrier?" Whatever the story of their distribution, only the careful preservation and recording of specimens will yield the final picture. Accumulation of specimens for positive identification and as permanent records of the fauna of the province is one of the many roles of the museum. Since the museum staff is limited in its field activities, procurement of specimens over a wide area is difficult. Interested per-

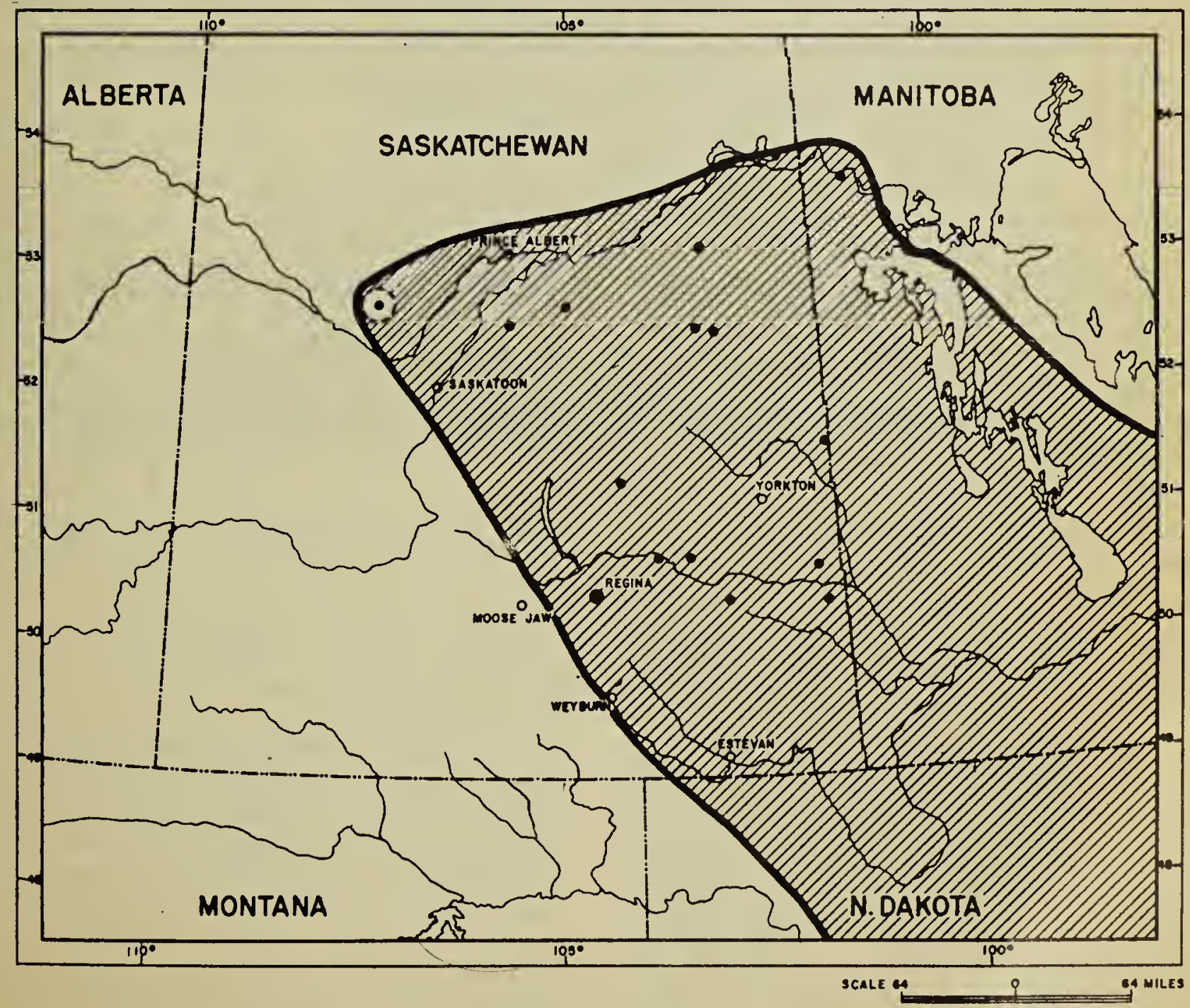

Range of the Shont-tailed Shrew in Saskatchewan and adjacent areas. Map prepared by Theo Kramer, Surveys Branch, Department of Natural Resources. 
sons are invited to contribute to this program." (Blue Jay, 14 (2): 45-46). In December, 1957, a specimen of a Short-tailed Shrew from Wakaw evoked the statement: "Judging by this new record this species occupies a range in Saskatchewan covering at least all of the parkland belt from the Manitoba border to the Saskatchewan River. .... It is questionable whether they appear north of the river since J. Dewey Soper did not find any in Prince Albert National Park. . . . However, only further collecting will provide the final answer." (Blue Jay, 15 (4):177).

Thanks to Mr. Pym we now have our answer; of course, this immediately raises the question again of the extent of their range. It is not much more than 115 miles west to the Alberta border and since the habitat appears to be conitinuously suitable, it seems possible that they may even occur in Alberta. This should give cur members in that area something to search for, and we hope that others will be as lucky as Mr. Pym who caught this shrew in a mouse trap which he had set in his barn.

Data on some Short-tailed Sinew specimens not recorded in Beck's Guide to Sask. Mammals (1958. Saskatchewan Natural History So- cicty, Spec. Pub. \#1) which represent new locality records follows: Rocanville, about 1950 -E. Symons; Rocanville, November 16, 1957-E. Dunsmcre; Ethelton, January 14, 1959Miss G. Belliveau; Madge Lake, September 3, 1959-R. W. Nero.

The map is based on these records as well as available Sask. specimens which have been previously reported (Blue Jay, 14:45; 15:121,-177). The range in adjacent areas is based on a map in a recent publication by $\mathrm{E}$. Raymond Hall and Keith R. Kelson (1959. Mammals of North America. Vcl. I, p. 53, Ronald Press Co., New York). A single recent record from The Pas, Manitciba, has been included. The dcts on the map represent actual locality records but the outlined range merely indicates the prcbable occurrence. It is expected, of course, that this species will not be found everywhere within this range, but probably wherever there is suitable habitat. It is thus of equal importance to cbtain specimens from additional localities within as well as cutside of this area. It is essential that we determine, for example, the precise limits of their penetration into the prairie along the line between Keatley, Regina and North Dakota, where the habitat appears to be marginal.

\section{Another Melanistic Snowshoe Rabbit}

By R. W. Nero, Saskatchewan Museum of Natural History.

The relative scarcity of melanistic specimens of the Snowshoe Rabbit (or Varying Hare) (Lepus americanus) has been indicated by $R$. D. Bird (1955. Melanism in the Varying Hare, Lepus americanus Erxleben. Canad. Field Nat., 69:11) and R. Velich (1956. Mammals frcm eastern Nebraska. Journ. Mamm. 37: 271272). Bird lists five records from Cunada: one from Quebec, three frcm Ontario and one from Marchwell, Sask. Another specimen was recently taken not far frcm the latter locality. On Dec. 13, 1955, Nick Bauer shot a black Snowshoe Rabibit at Waldron, Sask., 40 miles west of Marchwell. The specimen was submitted to the Museum by Jack Shaver, Wildlife
Branch, Department of Natural Resources, and was mounted. This rabbit is overall very dark blackishgrey, and in some light is almost silvery. It is darkest on the ears (nearly black) and palest on the lower limbs except that the feet are darker. The pads are a dirty grey color and the nails are dark to light grey. There are cocasional white hairs scattered throughout the pelage and there is a small cluster of white hairs in the center of the forehead. Data is not available on the eye color. According to J. Shaver reports have been received by the Wildlife Branch of at least two other b'ack rabbits, both presumably Snowshoe Rabbits-one near Asquith (about 1947) the other near Theodore (about 1952). 